\title{
José Ignacio Martínez Rodríguez
}

\author{
1956-2016
}

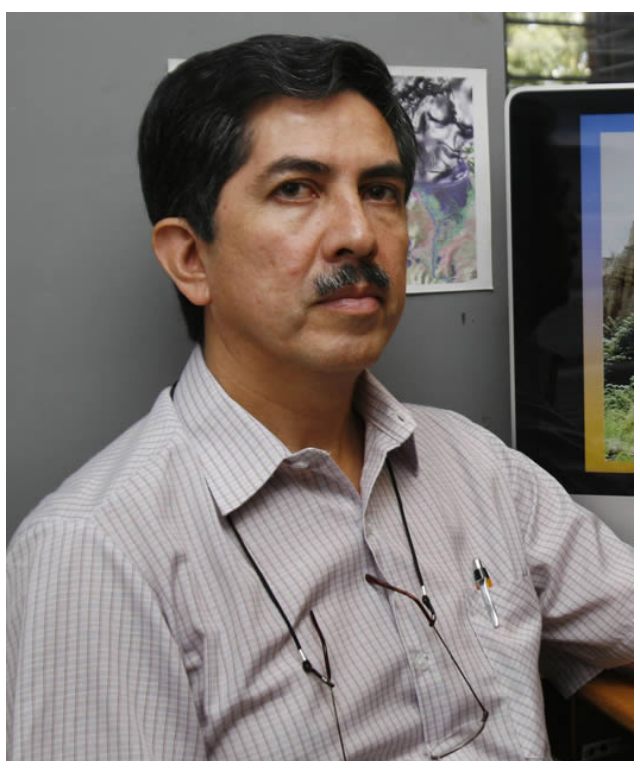

El clima de los últimos 2.7 millones de años es bastante inusual en la historia geológica de nuestro planeta, ya que combina cuatro atributos climáticos que rara vez se dan en conjunto. Estos son: un alto gradiente de temperatura latitudinal, hielo permanente en el Ártico, niveles de $\mathrm{CO}_{2}$ por debajo de 200 ppm, y un alto gradiente de temperatura meridional a lo largo del océano Pacífico tropical. Es en este último punto, que José Ignacio Martínez hizo aportes muy importantes a la ciencia. José Ignacio realizó múltiples investigaciones sobre la piscina caliente en el Pacifico occidental durante el Pleistoceno, en especial del Mar de Tasmania, y señaló cómo ésta se relacionaba con el gradiente longitudinal de temperatura a lo ancho del Ecuador, desde el Pacífico Oriental hasta el Occidental. José Ignacio también hizo aportes importantes para entender como este gradiente variaba durante los periodos glaciales/interglaciales. Estos estudios los complementó con una serie de investigaciones en el Pacífico ecuatorial occidental al estudiar la cuenca de Panamá y el margen del Pacífico Colombiano, donde encontró que durante periodos glaciales la corriente de chorro superficial del Chocó, uno de los principales componentes del clima de Colombia, se intensificaba, transportando grandes cantidades de aire húmedo del Pacifico ecuatorial hacia la Cordillera Central, posibilitando así el rápido desarrollo de los glaciares Andinos. Los resultados de su vida como investigador son ahora utilizados para entender y predecir el clima tropical, y en especial el colombiano, durante el cambio climático que nuestro planeta experimenta en la actualidad.

José Ignacio empleaba los foraminíferos, pequeños organismos que viven en los océanos, como herramienta principal en su investigación. Era uno de los líderes en este campo en toda Latinoamérica. Esa experticia en foraminíferos, también hizo que parte de su investigación se enfocara en el uso de estos microorganismos como herramientas bioestratigráficas y paleoecológicas a diversas escalas de tiempo, desde el Cretácico superior del Oriente colombiano, hasta modelos bioestratigráficos para el Cenozoico del Caribe Colombiano, investigaciones que son y seguirán siendo consultadas por geólogos durante muchas décadas. Durante los últimos años, José Ignacio estudió además el cambio climático del Holoceno tardío a través de las terrazas sedimentarias del río Cauca.

José Ignacio Martinez nació en Bogotá el 15 de mayo de 1956. Sus padres fueron Don José Martinez y Doña Narcisa Rodríguez. Lo sobreviven su esposa Ingrid Escobar y sus hijos Luisa y Daniel. En la Universidad Nacional de Colombia en Bogotá recibió el título de geólogo en 1982. Posteriormente se vinculó a Ingeominas. Luego fue becado por el gobierno británico para adelantar estudios de maestría en micropaleontología en Hull University, la cual finalizó en 1987. Al terminar este programa universitario regresó a Colombia para continuar trabajando en Ingeominas y como consultor micropaleontológo para la industria del petróleo. En 1990 fue becado por el gobierno australiano, donde realizó estudios de doctorado en la Australian National University, hasta el año 1994. A su regreso a Colombia se vinculó con el Instituto Colombiano del Petróleo por dos años. Sin embargo, su amor y dedicación por la investigación del Pleistoceno/Holoceno lo motivó a aceptar un postdoctorado ofrecido por la Australian National University para regresar nuevamente a Colombia en 1998 y vincularse como profesor del Departamento de Geología de la Universidad EAFIT (Medellín), posición que conservó durante los últimos 18 años.

Participó en numerosos cruceros oceanográficos, incluyendo el ODP 134 en Vanuatu, FR2 y FR10 en el océano Indico, Nemo3 y Amadeus en el Pacifico ecuatorial oriental, y Knoee 176 en la cuenca de Panamá. José Ignacio fue miembro del consejo editorial de la revista Palaeogeography, Palaeoclimatology, Palaeoecology, del comité científico de PAGES (Past Global Changes - IGBP), miembro correspondiente de la Academia Colombiana de las Ciencias Exactas, Físicas y Naturales y editor asociado de la Revista de la Academia. 
José Ignacio recibió también menciones como mejor profesor de la carrera de Geología en EAFIT, el premio anual de investigación de la Universidad EAFIT y una mención de Honor en Ciencias Naturales de la Fundación Alejandro Ángel Escobar. Su producción intelectual quedó registrada en más de sesenta artículos científicos en revistas internacionales y nacionales, lo que lo acredita como uno de los científicos colombianos más productivos y de mayor reconocimiento internacional en la historia de la Geología Colombiana.

Muchos de sus estudiantes disfrutaron al reconocer la belleza y los misterios del mundo natural a través de la ciencia. Su respeto y su trato siempre amable, su paciencia, alegría, calma y seguridad para actuar, su pasión por la ciencia, franqueza para expresar sus ideas de una manera siempre respetuosa, con rigurosidad científica, además de su conocimiento amplio y profundo contribuyó a que todos los que trabajamos con él llegáramos a ser mejores personas. José Ignacio enseñaba con el ejemplo de su diario vivir.

Extrañaremos mucho su fino humor, ácido y oportuno. Ese uso inteligente de palabras para contar chistes y hacernos reír. También extrañaremos su oficina siempre abierta para debatir no solo sobre ciencia sino para ofrecer sus consejos sobre muchas cosas más. Hoy le damos una despedida, demasiado temprana, a nuestro mentor, maestro, colega y amigo. Siempre lo recordaremos.

\section{Carlos Jaramillo}

Académico correspondiente de la Academia Colombiana de Ciencias Excatas Físicas y Naturales Smithsonian Tropical Research Institute, Panamá

\section{Jaime Escobar}

Universidad del Norte, Barranquilla 